\title{
Influence of Work Related Factors and Lifestyle on Work Ability among Construction Workers, West Bengal, India
}

\section{Anindita Mandal (Majee) $)^{1} *$ \& Suva Paul ${ }^{2}$

\begin{abstract}
${ }^{1}$ Associate Professor, ${ }^{2}$ Research Worker, Department of Physiology, Raja Peary Mohan College, University
\end{abstract} of Calcutta, West Bengal, India.}

\section{Corresponding Author}

Author Email:

anindita11us@rediffmail.com

DOI: $10.38177 / A J B S R .2020 .2203$

\section{Introduction}

In order to prevent workers from quitting the workforce due to work related disability, the concept of work ability has developed
Abstract: Introduction-The Work Ability Index (WAI) is a valuable used tool in occupational health to identify and avoid early retirement and work related disability. Purpose-To assess the work ability of construction workers of West Bengal and its relationship with risk factors. Methods-A cross sectional study was carried out among 25construction workers of semi urban area of Hooghly district of West Bengal by simple random sampling method. Body composition parameters and demographic details were recorded. Work ability and work ability index were measured by questionnaire. Results-4\% Construction workers have poor WAI, $88 \%$ have moderate and $8 \%$ have good WAI. None was present in excellent category of WAI. The average WAI was 32.92. There was a negative correlation between WAI and body composition parameters like height, weight, percentage of body fat. In the present study effects of hypertension and Musculo-skeletal disorder on WAI have also been found. Conclusion-According to the results of this present study aging, year of service, illiteracy, smoking habit decline the health status of construction workers thereby increasing the risk of presenting moderate or poor work ability.

Keywords: Work Ability, Work ability Index (WAI), Construction workers.

a valuable tool to tailor interventions at individual level. The concept of work ability expresses the interrelation between the productive potential of a worker, the worker's individual characteristics and work related factors [1,2]. Thus, the assessment of work ability should measure the ability of workers to perform their jobs, taking into account the specific psycho-social and physical work related factors, mental and physical capabilities and health too. On the basis of this concept, Finnish researchers have constructed the so called Work Ability Index (WAI), which is based on a questionnaire that combines subjective experience of one's ability to cope with physical and mental requirements at work with information on disease and sick leave [3].

The work ability index (WAI) has been promoted in recent years as a valuable tool in occupational health programs dedicated to decrease early exit from work place [4].Because of varying demands of work tasks, the same disease, injury or limitation in functional capacity may have a different effect on work ability [3]. Kaleta et al. [5] and Seitsamo \& Ilmarinen [6] established that life style characteristics such as physical activity in leisure 
time can also affect work ability. There is also a clear association between various diseases and poor work ability [7].

Thus assessment of work ability during occupational health examination and association with life style factors, indicates work related disabilities and early exit from the job. In this part of study a small number of sample was taken to assess the work ability of construction workers of West Bengal and its relationship with risk factors like BMI, smoking habit, year of service and cardio-vascular diseases.

\section{Methods}

\section{Determination of Work ability}

In order to assess the work ability of construction workers and its relation with job factor, life style and health status, 25 male construction workers were selected and a questionnaire of work ability has been filled by expert surveyor.

Work ability was measured by work ability index (WAI). It consists of an assessment of the physical and mental demands of people in relation to their work, diagnosed diseases, and limitations in work due to disease, sick leave, work ability, prognosis and psychological resources. The WAI constituted of seven dimensions, and the index is derived as the sum score of the rating on each dimensions. The range of summative index is 7-49.

Chart 1. Classification of Work Ability Index [8]

\begin{tabular}{|c|c|}
\hline WAI & $\begin{array}{c}\text { Category of } \\
\text { Work ability }\end{array}$ \\
\hline $\mathbf{7 - 2 7}$ & Poor \\
\hline $\mathbf{2 8 - 3 6}$ & Moderate \\
\hline $\mathbf{3 7 - 4 3}$ & Good \\
\hline $\mathbf{4 4 - 4 9}$ & Excellent \\
\hline
\end{tabular}

WAI determination was first published by Tuomi et al. [9] and validated by Martinez et al. [10] and Silva Junior et al. [11]

Work ability was measured by a questionnaire based index from the following 7 items.

i. Current work ability compared with a life time best ( 0 - 10 points)

ii. Work ability in relation to both physical and mental demand of work (2-10 points).

iii. Number of current diseases ( $1-7$ points) 
iv. Estimated work impaired due to diseases ( $1-6$ points)

v. Sick leave during the past year ( 12 months )

vi. Own prognosis of work ability 2 years from now $(1,4$ or 7$)$

vii. Mental resources ( enjoying daily task, activity and life spirit ) ( 1-4 points)

Subjects at or below 36 points were classified as having low work ability while those above 37 points were having satisfying work ability [12]. At the same visit, body height and body weight, percentage of body fat from skinfold thickness [13,14] and waist:hip ratio[15] were measured. BMI was calculated from body weight and body height. BMI =wt $(\mathrm{kg}) /$ height in $(\mathrm{m})^{2} \mathrm{Kg} / \mathrm{m}^{2}$. Systolic and diastolic blood pressures were measured by auscultatory method using sphygmomanometer and stethoscope in sitting condition.

Classification of hypertension (JNC-VII, 2003) [16].

\begin{tabular}{|l|l|l|}
\hline $\begin{array}{l}\text { Categories of } \\
\text { hypertension }\end{array}$ & $\begin{array}{l}\text { Systolic Blood Pressure } \\
(\mathrm{mm} \mathrm{Hg})\end{array}$ & $\begin{array}{l}\text { Diastolic Blood Pressure } \\
(\mathrm{mm} \mathrm{Hg})\end{array}$ \\
\hline Normal & $<120$ & $<80$ \\
\hline Pre-hypertension & $120-139$ & $80-89$ \\
\hline Mild hypertension & $140-159$ & $90-99$ \\
\hline Moderate hypertension & 160 & 100 \\
\hline Severe hypertension & $\geq 180$ & $\geq 110$ \\
\hline
\end{tabular}

\section{Determination of pain intensity}

For each body region, the 7 day prevalence of musculo -skeletal symptoms was assessed by question on a scale ranging from $0-10$ ( $0=$ no pain, $10=$ pain as bad as it could be [17].

\section{Statistical analysis}

All data have been expressed in terms of mean \pm SD. Correlation, t-test, Odds ratio with $95 \%$ confidence interval have been performed to assess the risk by statistical package (SPSS 16.0).

\section{Results}

Table 1 represents the demographic characteristics of the participated construction workers. $68 \%$ construction workers are in lower age group and $32 \%$ are in higher age group. Regarding smoking habit $76 \%$ construction workers are smokers and $24 \%$ are 
non-smokers. Among construction workers $68 \%$ are mason and $32 \%$ are labour. Regarding year of service $64 \%$ construction workers have $<10$ years of service and $36 \%$ have $>10$ years of service. $84 \%$ construction workers are literate and $16 \%$ are illiterate.

Table 1. Demographic pattern of study population

\begin{tabular}{|c|c|c|c|}
\hline \multirow[t]{2}{*}{$\begin{array}{c}\text { Socio-demographic } \\
\text { characteristics }\end{array}$} & \multicolumn{3}{|c|}{$\begin{array}{l}\text { Construction workers } \\
\qquad(\mathrm{n}=25)\end{array}$} \\
\hline & & No. & $\%$ \\
\hline \multirow{2}{*}{ Aging } & $15-35$ yrs & 17 & 68 \\
\hline & $36-60$ yrs & 08 & 32 \\
\hline \multirow{2}{*}{ Smoking habit } & Smokers & 19 & 76 \\
\hline & Non-smokers & 06 & 24 \\
\hline \multirow{2}{*}{ Type of work } & Mason & 17 & 68 \\
\hline & Labour & 08 & 32 \\
\hline \multirow{2}{*}{ Year of service } & $<10$ yrs & 16 & 64 \\
\hline & $>10$ yrs & 09 & 36 \\
\hline \multirow{2}{*}{$\begin{array}{l}\text { Educational } \\
\text { qualification }\end{array}$} & Illiterate & 04 & 16 \\
\hline & Literate & 21 & 84 \\
\hline
\end{tabular}

Table 2 represents work ability index (WAI) of construction workers. It is observed that 4\% workers have poor WAI (7-27), 88\% workers have moderate WAI , $8 \%$ workers have good WAI. None has excellent WAI in our study.

Table 2: WAI of Construction workers

\begin{tabular}{|c|c|c|c|c|}
\hline Grade & No. & $\%$ & WAI & Average WAI $(n=25)$ \\
\hline Poor (7-27) & 01 & 04 & 27 & \multirow{2}{*}{32.92} \\
\hline Moderate (28-36) & 22 & 88 & 32.82 & \multirow{2}{*}{37} \\
\cline { 1 - 3 } Good (37-43) & 02 & 08 & 37 & \\
\hline Excellent (44-49) & - & - & - & \\
\hline
\end{tabular}


Table 3 represents mean values of work ability and work ability index of higher and lower age group, smoker and non-smokers, $<10$ yrs and $\geq 10$ years of service of construction workers. Lower age group when compared with higher age group, smokers compared with non- smokers , < 10 yrs compared with $\geq 10$ years of service do not show any significant difference in work ability and work ability index.

Table 3: Work ability index of different groups of construction workers

\begin{tabular}{|c|c|c|c|c|c|c|}
\hline \multirow{2}{*}{ Age group } & \multicolumn{2}{|c|}{$\begin{array}{c}\text { Workers with MSD } \\
(\mathrm{n}=12)\end{array}$} & \multicolumn{2}{c|}{ Workers with hypertension } \\
& No. & $\%$ & $\begin{array}{r}\text { Mea } \\
n \\
\text { WAI }\end{array}$ & No. & $\%$ & Mean WAI \\
\hline $18-35$ yrs. $(n=17)$ & 05 & $\begin{array}{c}41 . \\
6\end{array}$ & $\begin{array}{c}33 . \\
2\end{array}$ & 05 & 50 & 33.2 \\
\hline $36-60$ yrs. $(n=08)$ & 07 & $\begin{array}{c}58 . \\
3\end{array}$ & $\begin{array}{c}33 . \\
14\end{array}$ & 05 & 50 & 32.0 \\
\hline
\end{tabular}

Table 4: WAI of lower and higher age group construction workers with regard to prevalence of MSD (Musculo-skeletal disorder) and hypertension

\begin{tabular}{|l|l|l|l|l|l|l|}
\hline Parameters & $<10 y r s$ & $\geq 10 y r s$ & Lower age & Higher age & Smokers & $\begin{array}{l}\text { Non } \\
\text { smokers }\end{array}$ \\
& $(n=16)$ & $(n=09)$ & $(n=17)$ & $(n=08)$ & $(n=19)$ & $(n=06)$ \\
WA & $4.85 \pm 0.72$ & $4.73 \pm 0.34$ & $4.87 \pm 0.69$ & $4.66 \pm 0.36$ & $4.73 \pm 0.40$ & $5.05 \pm 1.05$ \\
\hline WAI & $32.81 \pm 2.71$ & $33.11 \pm 2.37$ & $33.06 \pm 2.63$ & $32.63 \pm 2.50$ & $33.11 \pm 2.79$ & $32.33 \pm 1.63$ \\
\hline
\end{tabular}

Table 4 represents WAI of lower and higher age group construction workers suffered from musculo-skeletal disorder (MSD) and hypertension. It has been observed that $41.6 \%$ lower age group and 58\% higher age group construction workers suffer from MSD but 50\% lower and higher age group construction workers had MSD as well as hypertension. No significant difference in work ability has been found in between lower and higher age group of workers in the prevalence of MSD but WAI of hypertensive higher age group workers is lower than 
lower age group workers indicating risk of hypertensive higher age group workers for early retirement and absenteeism as well as loss of productivity.

Table 5 represents WAI of mason and labour group of construction workers with regard to prevalence of MSD and hypertension. It is found that $92 \%$ mason and $8 \%$ labour workers suffered from MSD but $70 \% \& 30 \%$ of the above mentioned group respectively showed hypertension indicating most stressful pattern of job. It is found that WAI of mason workers of having MSD and hypertension is significantly lower than labour workers and similar result has been observed incase of hypertensive workers of the above two categories indicating difference in stressful working condition in these two groups of workers.

Table 5: WAI of Mason and labour with regard to prevalence of MSD and hypertension

\begin{tabular}{|l|c|c|c|c|c|c|}
\hline \multirow{2}{*}{ Type of work } & \multicolumn{3}{|c|}{ Workers with MSD ( $\mathrm{n=}$} & \multicolumn{3}{c|}{ Workers with } \\
& No. & $\%$ & $\begin{array}{c}\text { Mean } \\
\text { WAI }\end{array}$ & No. & $\%$ & $\begin{array}{c}\text { Mean } \\
\text { WAI }\end{array}$ \\
\hline Mason ( $\mathrm{n}=17)$ & 11 & 91.7 & 33 & 07 & 70 & 32.14 \\
\hline Labour $(\mathrm{n}=08)$ & 01 & 08 & 25 & 03 & 30 & 33.67 \\
\hline
\end{tabular}

Table 6: Effect of BMI, smoking habit and year of service on WAI of two groups of construction workers

\begin{tabular}{|c|c|c|c|c|c|c|c|}
\hline \multirow{2}{*}{\multicolumn{2}{|c|}{ WAI }} & \multicolumn{2}{|c|}{ BMI } & \multicolumn{2}{|c|}{ Smoking habit } & \multicolumn{2}{|c|}{ Year of service } \\
\hline & & $\begin{array}{c}\geq 22 \\
\mathrm{~kg} / \mathrm{m}^{2} \\
(\mathrm{n}=09)\end{array}$ & $\begin{array}{c}<22 \\
\mathrm{~kg} / \mathrm{m}^{2} \\
(\mathrm{n}= \\
16)\end{array}$ & $\begin{array}{c}\text { Yes } \\
\left(\begin{array}{c}n= \\
19)\end{array}\right.\end{array}$ & $\begin{array}{l}\text { No } \\
(\mathrm{n}= \\
06)\end{array}$ & $\begin{array}{c}\geq 10 \\
\text { years } \\
(\mathrm{n}= \\
09)\end{array}$ & $\begin{array}{c}<10 \\
\text { years } \\
(n=16)\end{array}$ \\
\hline Gr. 1 (Poor or & $\mathrm{n}$ & 08 & 15 & 17 & 06 & 08 & 15 \\
\hline$[\mathrm{n}=23]$ & $\begin{array}{l}\text { WAI } \\
\text { Mean }\end{array}$ & 33.38 & 32.71 & 32.65 & 32.33 & 32.71 & 32.53 \\
\hline Gr. 2 (Good or & $\mathrm{n}$ & 01 & 01 & 02 & - & 01 & 01 \\
\hline
\end{tabular}




\begin{tabular}{|c|c|c|c|c|c|c|c|}
\hline $\begin{array}{c}\text { excellent }) \\
{[\mathrm{n}=02]}\end{array}$ & WAI & 37 & 37 & 37 & - & 37 & 37 \\
\hline OR & 1.88 & 1 & 1.7 & 1 & 1.88 & 1 \\
\hline $95 \% \mathrm{CI}$ & $\begin{array}{c}0.03-9 . \\
71\end{array}$ & & $\begin{array}{c}0.13-2 \\
2.87\end{array}$ & & $\begin{array}{c}0.10-3 \\
4.13\end{array}$ & \\
\hline
\end{tabular}

Table 6 represents comparison of two groups (poor or moderate and good or excellent) of construction workers in terms of body mass index (BMI), smoking habit and years of exposure. The frequency of those with good or excellent work ability was significantly higher than those with poor or moderate work ability in case of smoker, BMI $\geq 22 \mathrm{~kg} / \mathrm{m} 2 \& \geq 10$ years of service $(P<0.05)$ ( OR ranges from $1.7-1.88)$. Table 7 represents correlation between WAI with body composition parameters among construction workers. The correlation values with WAI are negative but insignificant indicating that work ability decreases with increase in body weight, body height and \% of body fat.

Table 7. Correlation of BMI \& WAI with body composition parameters

\begin{tabular}{|l|l|l|l|l|l|l|}
\hline & BMI & WAI & Height & Weight & $\%$ BF & W:H \\
\hline BMI & 1 & 0.02 & 0.20 & $0.92 * *$ & $0.63 * *$ & 0.07 \\
\hline WAI & 0.02 & 1 & -0.15 & -0.06 & -0.09 & 0.03 \\
\hline
\end{tabular}

Fig 1 indicates WAI of different educational level of workers with respect to MSD and hypertension.

It is observed that WAI is significantly higher in illiterate workers with MSD and hypertension in comparison with primary and secondary level of education.

Figure 1: Comparison of WAI of construction workers with different level

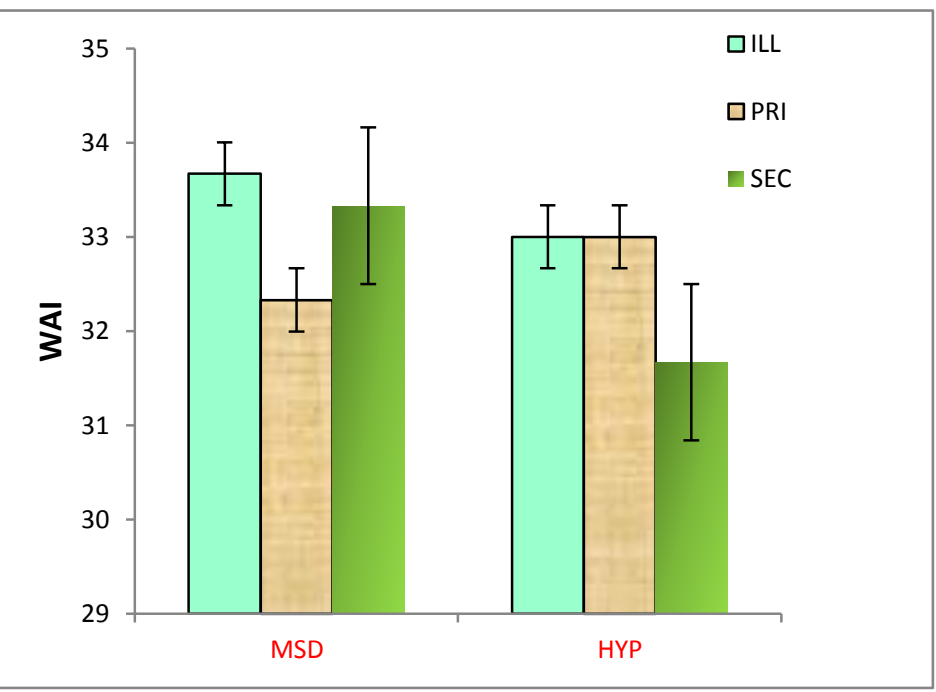
of education (ILL -Illiterate, PRI- Primary, SEC - Secondary) with respect to prevalence of MSD (Musculo-skeletal disorder) \& hypertension (HYP). 


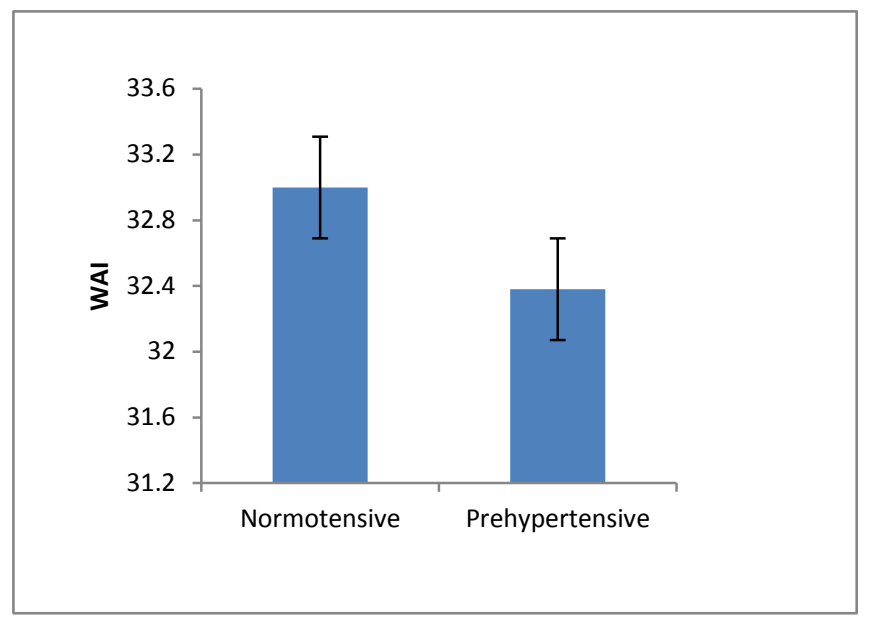

As regards Work Ability Index (WAI) values of normotensive workers when compared with work abilities of workers of pre-hypertension it was observed that workers with pre-hypertension had lower work ability than normal healthy workers (Fig 2).

Figure 2: Comparison of the WAI between normotensive \& prehypertensive workers.

Again WAI when classified according to the BMI levels $\left(16-19 \mathrm{~kg} / \mathrm{m}^{2}, 20-22 \mathrm{~kg} / \mathrm{m}^{2}\right.$ and $>22 \mathrm{~kg} / \mathrm{m}^{2}$ ), it has been found that work ability increases with increase in BMI level, indicating the role of nutritional status on work ability (Figure 3 ).

Figure 3: Comparison of WAI of workers among different categories of BMI

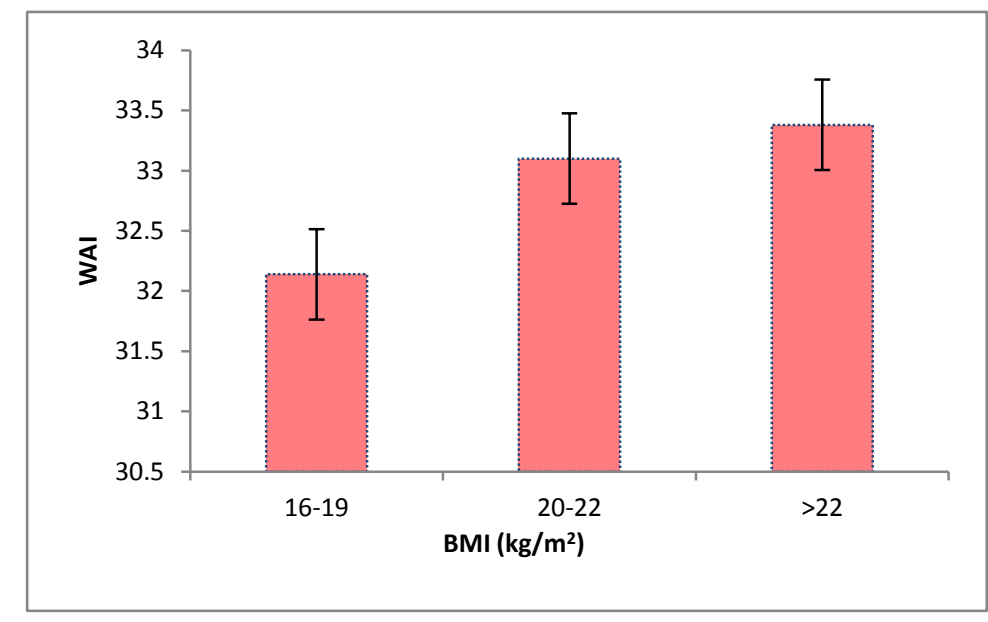

\section{Discussion}

In the present study the WAI of construction workers was 4\% (poor), 88\% (moderate) and $8 \%$ (good). None was present in excellent category of WAI and the average WAI was 32.92. Mohammadi et al.[18] found that average WAI of manufacturing workers of Tehran was 41.9. The difference might be due to cultural difference, level of education and life style factors [19]. But Jedryka - Goral et al. [20] reported that workers suffering from osteoarthritis (OA) and rheumatic and cardiologic problems had moderate or good work ability which corroborated with our study. Again, Pohjonen [2] indicated that 40-44 was the critical age for decrease in work ability but according to Ilmarinen et al. [21] it was 51 years which was similar to our study, as WAI of higher age group (36-60 yrs) hypertensive workers was significantly lower than lower age group (18-36 yrs). It might be concluded 
that among workers with chronic diseases, work ability decreases due to disease rather than age [19].

In the present study work ability is higher with lower education level. In contrast, Jedryka - Goral et al. [20] found that higher the education level, the better the work ability, the difference was statistically significant in patients and in control group. This difference in result might be due to less number of subject in the present study.

In the present study WAI of mason with MSD and hypertension is lower than labour workers. Again, higher age group hypertensive workers have poor WAI than lower age group. These results indicate that work ability in aging workers is closely linked to health status [19]. Similar opinion has been stated by Kiss et al. [22] and they observed that WAI is mostly influenced by age and by health - firstly, by problems of locomotion and secondly, by problems of cardio vascular and respiratory system among fireman. Alavinia et al. [23] observed that pulmonary problems showed a negative association with work ability and these associations were not influenced by work related factors. They also concluded that high physically demanding jobs like construction industry, psychological and physical work related factors are most important factors associated with work ability. Besides, in work places with high physical loads ergonomic interventions are of great importance to maintain work ability of workers. Eyler et al. [24] reported that lower the risk of several diseases like cardio-vascular disease, musculo-skeletal disease and diabetes (type 2) higher will be the work ability. Therefore, when trying to improve work ability of workers, their health status must be looked after carefully. Besides, in order to improve work ability, nutritional status, environmental factors, proper organization of work and work ability after work time should be carefully considered in order to offer workers due relaxation time after their working day. Again, it is also important to lay emphasis on medical expenses, family obligation of chronically ill-aging workers that will influence the work ability among workers by giving mental support.

It was also suggested by Tuomi et al. [4] that work ability could be improved by decrease in repetitive movements, an improvement in supervisor's attitude and increase in physical exercise [25]. Pohjnen [2], Tuomi et al. [7,24] reported that poor work postures and repetitive movements were associated with an impaired ability to work. But Lindberg et al. [26] indicated the development of a poor work ability can be prevented by controlling the organizational and psychological factors. Tuomi et al. [25] also stated that unhealthy life styles of industrial workers are considered an important factor with respect to work ability. 
Again Nurminen et al. [27] suggested that moderate level of exercise has positive effect on perceived work ability.

In our study, from questionnaire analysis, construction workers do not participate any physical exercise in their leisure time which might be the reason for their poor to moderate work ability.

In the present study WAI values increase with increase in BMI and maximum value (33.38) has been observed with well nourished $\left(B M I>22 \mathrm{~kg} / \mathrm{m}^{2}\right)$ workers than under nourished ones (BMI 16-19kg/m²). But Mohammadi et al.[17] observed that workers with BMI $>25 \mathrm{~kg} / \mathrm{m}^{2}$ had poor and moderate work ability than lower BMI. Kaleta et al. [18] showed that overweight women had 2 times greater risk of moderate and poor WAI than those with appropriate weight (adjusted $\mathrm{OR}=2.33,95 \% \mathrm{CI}=1.09-7.96$ ). Odds ratio values indicate that smoking habit and year of service enhance the risk of diminishing work ability. Similar results have been reported by Mohammadi et al. [17] and he stated that risk of poor or moderate WAI for smokers was 2.8 times significantly greater than non smokers. Kaleta et al. [16] observed significant relation between smoking and poor WAI among males and females. According to WHO [28] there is a negative relation between smoking and health status which can affect the WAI. Thus, the present study focused that there might be a relationship between work ability, physical factors and environmental factors and life style (BMI, smoking habit and physical activity). Therefore, it is recommended for implementation of educational programme for prevention of smoking habit, intake of healthy diet and physical exercise in order to enhance work ability and occupational health quality in working environment. To prevent early retirement and improve the workability, it is necessary to implement ergonomics and occupational health programmes. Besides, improvement of employer's support, reduction in job demand, improvement in sleep quality, mental support regarding family liability, supportive wages, medical benefits and leisure time physical activity will be of great concern for enhancement of the work capacity by overcoming the health related problems.

\section{Acknowledgement}

Authors are thankful to UGC for their financial support for successful completion of this work.

\section{References}

1.D H Wegman, Older workers. Occup Med. 14 (3), 1999, 537-57.

2.T Pohjonen, Percieved work ability of home care workers in relation to individual and work-related factors in different age groups. Occup Med (Lond)., 51 (3), 2001, 209-17. 
3.J Ilmarinen, , K Tuomi,L Eskelinen, C H Nygard, P Huuhtanen, M Klockars,Background and objectives of the Finnish research project on aging workers in municipal occupations. Scand J Environ Health., 17 Suppl 1, 1991,7-11.

4.K Tuomi, P Huuhtanen, E Nykyri, J Ilmarinen, Promotion of work ability, the quality of work and retirement . Occup Med ( Lond ).,51 (5), 2001,318-24.

5.D Kaleta,, T Makowiec - Dabrowska, A Jegier, Leisure -time physical activity cardio respiratory fitness and work ability : a study in randomly selected residents of Lodz. Int J Occup Med Environ Health., 17 (4), 2004 ,57-64.

6.J. Seitsamo, J. Ilmarinen, Life style, aging and work ability among active Finnish workers in 1981-1992. Scand J Environ Health. 23 Suppl 1, 1997, 20-6.

7. K.Tuomi, J. Ilmarinen, L. Eskelinen, E. Jarvinen, J. Toikkanen, M. Klockars, Prevalence and incidence rates of diseases and work ability in different work categories of municipal occupations. Scand J Environ Health. 17 Suppl 1,1991,7-74.

8.K.Tuomi, J.Ilmarinen, A.Jahkola, L.Katajarinne, A.Tulkki, Work Ability Index. 2nd revised ed, Helsinki, Finland : Finish Institute of Occupational Health,1998.

9.K. Tuomii, J. Ilmarinen, L. Katajarinne, A. Tulkki, Indice de Capacidade para o Trabalho. 1a ed. Sao Carlos: EDUFSCAR, 2005

10. M.C.Martine,M. Latorre,F.M Fischer, Validade e confiabilidade da versao brasileira do indice de Capacidade para o Trabalho. Rev Saude Publica. 43, 2009, 525-32.

11. S.H.A.da Silva junior, A.G.G.R.H.Griep,L. Rotenberg. Validade e confiabilidade do indice de capacidade para o trabalho (ICT) em trabalhadores de enfermagem . Cad Saude Publica 27, 2011,1077-87.

12. J.Bresic, B.Knezevic, M.Milosevic, T.Tomljanovic, R. Golubic,J. Mustaibegovic, Stress and work ability in oil industry workers. Arh Hig Rada Toksikol. 58, 2007,399-405.

13. A.W. Solan, Estimation of body fat in young men. Journal of Applied Physiology. 23, 1967,311-315. 14. W.E.Siri, Gross composition of the body. Advances in Biological and Medical Physics ((J.H.Lawerence and C.A.Tobians, eds) New York : Academic press, 1961.

15. R.Valdez,J.C Seidell, Y.I.Ahn,K.M.Weiss, A new index of abdominal adiposity-an indicator of risk for cardiovascular diseases. A cross-population study. International Journal of Obesity, 17, 1993,77-82

16. The seventh report of the Joint National Committee on Prevention, Detection, Evaluation and Treatment of high blood pressure -complete report ( JNC - VII ), 2003

17. I.Kuorinka, B.Jonsson,A. Kilbom, et al. Standardised Nordic questionnaires for the analysis of musculo skeletal symptoms . Appl Ergon, 18, 1987, 233-237. 
18. S.Mohammadi,M.Ghaffari,A.Abdi,B.Bahadori,E.Mirzamohammadi,M.Attarchi, Interaction of life style and work ability index in Blue Collar Workers. Global Journal of Health Science. 7 (3), 2015, 90-97. 19. D.Kaleta, T.Makowiec - Dabrowska, A.Jegier, Lifestyle Index and work ability . Int J Occup Med Environ Health, 19 (3), 2006,170-177.

20. A.Jedryka - Goral, J.Bugajska, E.Lastowiecka, A.Najmiec, M.Rell-Bakalarska, I.Bownik, J.M.Michalak,M.Kochmanski. Work ability in aging workers suffering from chronic diseases. International Journal of Occupational Safety and Ergonomics. 12 (1), 2006, 17-30.

21. J.Ilmarinen, K.Tuomi, M.Klockars, Changes in the work ability of active employees over an 11-year period. Scand J Work Environ Health. 23(suppl 1), 1997,49-57.

22. P.Kiss, M.Walgraeve, M.Vanhoorne, Assessment of work ability in aging fire fighters by means of the work ability index preliminary results. APH, 60, 2004,233-43.

23. S.M.Alavinia, A.de Boer, M.G.E,J.C.van Duivenbooden ,M.H.W. Frings-Dresen, A.Burdorf, Determinants of work ability and its predictive value for disability. Occupational Med. 59, 2009,32-37 24. A.A.Eyler,R.C. Brownson, S.J.Bacak, R.A.Houseman, The epidemiology of walking for physical activity in the United States. Med Sci Sports Exerc . 35 (9), 2003, 1529-36

25. K.Tuomi, J.Ilmarinen, R.Martikainen, L.Aalto,M. Klockars, Aging, work, life style and work ability among Finnish municipal workers in 1981-1992. Scand J Work Environ Health. 23 suppl 1, 1997, 58-65 26. P.Lindberg, M.Josephson, L. Alfredson,E. Vingard, Promoting excellent work ability and preventing poor work ability: the same determinants? Results from the Swedish HAKUL study. Occup EnvironMed. 63 (2), 2006, 113-20.

27. E.Nurminen,A.Malmivaara,J.Ilmarinen,P.Ylostalo,P.Mutanen,G.Ahonen,etal. Effectiveness of a worksite exercise program with respect to perceived work ability and sick leaves among women with physical work. . Scand J Work Environ Health. 28 (2), 2002, 85-93.

28. World Health Organization (WHO). Tobacco or Health : A Global Status Report, 1997. 